\title{
Peningkatan Kualitas Pembelajaran Menggambar Mahasiswa Desain Produk Industri Melalui Media Ajar Cetak Dan Digital
}

\author{
Waluyohadi, Alya Nadira, Nuril Luaili, Nur Ameliyah Rizkiyah, dan Meila Amrina Rosyadah \\ Departemen Desain Produk, Fakultas Arsitektur Desain dan Perencanaan, \\ Institut Teknologi Sepuluh Nopember, Surabaya, Indonesia \\ e-mail: waluyohadi@gmail.com
}

\begin{abstract}
Metode pembelajaran mata kuliah Gambar/ Gambar Produk di Departemen Desain Produk ITS meliputi tutorial / classical, tugas dan asistensi. Dalam hal ini proses asistensi tidak sepenuhnya efisien karena rasionya 2 dosen mengasistensi 40-70 mahasiswa sehingga dalam 3 jam seorang dosen harus mengasistensi 20-35 mahasiswa. Artinya, 1 mahasiswa paling tidak asistensi maksimal selama 9 menit. Padahal untuk menjadi seorang desainer yang memiliki skill layak harus pernah menggambar semua obyek produk yang sangat banyak dan tak terbatas jumlahnya. Hal yang memungkinkan dilakukan adalah memaksimalkan waktu yang ada, menambah waktu yang ada, atau mencari waktu diluar perkuliahan. Penelitian ini menghasilkan modul ajar dan video demo riil menggambar yang merupakan dokumentasi proses menggambar mahasiswa seniornya untuk menggantikan tambahan waktu diluar kuliah yang nantinya digunakan mahasiswa sebagai referensi teknik menggambar dan bisa digunakan untuk belajar dirumah. Hal ini sangat efektif dan melatih mahasiswa agar lebih mandiri.
\end{abstract}

Kata kunci: Modul ajar, cetak, digital, gambar, dan desain

\begin{abstract}
The teaching method in the Basic Drawing subject in ITS Industrial Design Department consists of tutorial, practice, and one-on-one assistance. In this case, the process of one-onone assistance is not efficient mainly due to unbalance ratio of 2 lecturers who assist for 40-70 students. Therefor every lecturer must assist 20-35 students in about 3 hours. It means that 1 student has only 9 minutes to discuss with the lecturer about their project. Even though, student need to have more time and experience to learn drawing as design student. To solve this problem, students have to manage extra time outside the class to learn by their selves. This research proposes to arrange self-learning module and equipped with demo reel as a documentation of drawing process made by senior design student. It can also be a reference for the student to learn a drawing technique independently.
\end{abstract}

Keywords: Teaching module, printed, digital, drawing, design

\section{PENDAHULUAN}

Menggambar merupakan sebuah kecerdasan yang mengkoordinasikan antara visual, rasional, motorik tangan dan rasa. Hanya dengan proses pembelajaran yang lama, 4 unsur tersebut bisa terkoordinasi dan menghasilkan karya yang layak. Desain Produk Industri, sebagai departemen yang in-take mahas iswanya tidak in-line dengan kualifikasi lulusan SMA, maka kecerdasan kognitif khususnya kemampuan menggambar menjadi suatu hal yang perlu diperhatikan.

Ada satu kasus menarik tentang 2 tugas mata kuliah Gambar Bentuk yaitu gambar still life (alam benda) dan gambar mobil sebagaimana penulis alami saat mengajar di kelas tersebut. Dalam tugas ini nilai gambar still life lebih bagus dari pada nilai gambar mobil, walaupun sebenarnya tingkat kesulitan still life lebih tinggi dibandingkan mobil yang material obyeknya homogen. Ternyata permasalahannya sederhana, mahasiswa belum pernah membuat gambar mobil dan menggambar mobil dibutuhkan kecerdasan spatial yang tidak didapatkan di sekolah. Sedangkan gambar still life selalu dipelajari baik di tingkat SD, SMP, SMA dan bimbingan belajar. Disini dapat diambil kesimpulan sementara bahwa yang terpenting dalam menggambar bentuk adalah mahasiswa pernah "mengalami".

Di Departemen Desain Produk ITS, ada 3 metode yang digunakan dalam proses pembelajaran di kelas Gambar Bentuk dan Gambar Produk yaitu : tutorial, tugas dan asistensi. Dalam hal ini proses asistensi tidak sepenuhnya efisien karena rasionya 2 dosen mengasistensi 40-70 mahasiswa sehingga dalam 3 jam seorang dosen harus mengas istensi 20-35 mahas iswa, artiny a 1 mahas is wa paling tidak asistensi maksimal selama 9 menit. Hal yang memungkinkan dilakukan adalah memaksimalkan waktu yang ada, menambah waktu yang ada, atau mencari waktu diluar perkuliahan. Dan hal ini sangat relevan dengan nature belajar menggambar yang cenderung informal dan menyenangkan. ITB sebagai perguruan tinggi paling senior di Indonesia menggunakan media ajar multimedia berupa demo reel. Demo reel ini berupa dokumentasi proses menggambar seorang desainer atau artist/seniman yang nantinya digunakan mahasiswa sebagai referensi teknik menggambar dan bisa digunakan untuk belajar dirumah.

Dari permasalahan di atas, karena untuk menjadi seorang desainer yang memiliki skill layak harus pernah menggambar semua obyek produk, padahal obyek produk sangat banyak dan tak terbatas jumlahnya, maka akan muncul pertanyaan, bagaimana caranya agar mahasiswa "mengalami" semua proyek sedangkan waktu yang tersedia dibatasi 16 pertemuan? Dari sisi materi, obyek-obyek gambar apa sajakah yang perlu diprioritaskan dalam penyusunan silabus khususnya yang relevan dengan kebutuhan desainer produk, desainer komunikasi visual dan desainer interior? Bagaimana wujud medianya? Dari sini penulis merasa bahwa perlu adanya pemetaan materi 
masing-masing kuliah Gambar Bentuk di masing-masing departemen tersebut. sehingga didapatkan materi yang sesuai kebutuhan. Selain itu, di penelitian ini penulis bermaksud menerapkan hasil pemetaan tersebut sebagai modul ajar baik versi cetak maupun digital.

\section{Perumusan Masalah}

Dari uraian di atas, permasalahan yang muncul dan akan diteliti dapat dirumus kan sebagai berikut :

1. Perlunya pemetaan materi perkuliahan Gambar Bentuk / Gambar Produk di Departemen Desain Produk Industri, Desain komunikasi Visual, dan Desain Interior agar diperoleh materi yang paling sesuai dengan kompetensi mereka.

2. Bagaimana menerapkan materi tersebut ke dalam modul ajar cetak dan ber ISBN.

3. Bagaimana menerapkan materi tersebut ke dalam modul ajar digital (demo reel) sebagai pelengkap modul ajar cetak.

\section{Tujuan Penelitian}

Tujuan dilakukannya penelitian ini adalah sebagai berikut :

1. Untuk mengetahui materi-materi perkuliahan gambar bentuk yang sesuai dengan standar kompetens i Desainer Produk, Desainer Komunikasi Visual dan Desainer Interior.

2. Menyusun modul ajar versi cetak yang mendukung proses perkuliahan di dalam kelas.

3. Menyusun modul ajar versi digital yang mendukung proses pembelajaran di luar kelas.

\section{Manfaat Penelitian}

Dengan penelitian ini diharapkan dapat mendukung dan melengkapi proses perkuliahan terutama kemampuan menggambar secara mandiri dan terstruktur.

Untuk mengetahui sejauh mana permasalahan di atas telah diteliti oleh peneliti sebelumnya, maka dilakukanlah kajian pustaka beberapa literatur terkait rumus an masalah.

Teori Howard Gardner mengatakan bahwa pengukuran kecerdasan alami melalui tes IQ merupakan suatu hal yang terlalu dibatasi. Gardner membagi kecerdasan ini dalam 8 (delapan) kecerdasan inti bes erta operasi intinya [1], yaitu :

1. Linguistic (bahasa): sintak, ponologi semantik dan pragmatic.

2. Musical (musik): titi nada, irama, warna nada.

3. Logical-mathematical (logika matematik): angka, pengelompokan, hubungan.

4. Visua-Spatial (ruang): mental akurat visualisasi, mental perubahan bentuk/citra.

5. Bodily kinesthetic (gerakan badan): kendali atas badan sendiri, mengontrol dalam mengendalikan obyek.

6. Interpersonal: kesadaran tentang perasaan orang lain, emosi, tujuan motivasi.

7. Intrapersonal: kesadaran tentang perasaan diri sendiri, emosi, tujuan, motivasi.

8. Naturalist/alam: pengenalan dan penggolongan di dalam lingkungan.

Menurut teori Gardner, kecerdasan menggunakan dua pikiran sehat. Kecerdasan dapat juga menandakan perbedaan individu. Masing-masing orang mempunyai campuran atau gabungan dari beberapa kecerdas an tersebut secara berbedabeda. Kecerdasan visual-spatial membuat individu merasakan informasi yang tertangkap secara visual dan merekamnya dalam memori mereka. Kecerdasan visualspatial obyek dapat digambarkan sebagai berikut:

1. Peka terhadap hubungan antara garis, warna, bentuk, ruang dan bentuk.

2. Suatu kemampuan untuk menggerakkan dan memutar obyek.

3. Kapasitas untuk menciptakan grafis suatu benda.

4. Kemampuan untuk memahami komponen ruang dan visual di dalam seni grafis.

5. Seniman grafis, arsitek, navigator, pemahat, desainer, mekanik, insinyur, dan map-makers adalah contoh pekerjaan dengan kecerdas an visual-spatial.

6. Membaca peta, bermain catur, meggambar, dan menarik diagram, bermain teka-teki membangun, mengecat, menciptakan analogi dan kiasan visual, menggerakkan gambar, memperbaiki, merancang obyek praktis, penginterpretasian gambaran visual dan ilus trasi adalah aktivitas orang yang memiliki kecerdas an visual-spatial.

Kecerdasan visual-spatial dapat dikembangkan melalui beberapa pembelajaran yang diantaranya:

1. Mendesain suatu bangunan

2. Mempelajari sebuah gambar, dan menggambarkannya kembali tanpa mengacu pada gambar tersebut.

3. Belajar suatu gambar, kemudian mendeskripsikan apa yang ada di balik gambar tersebut.

4. Mengembangkan mind-map untuk area studi yang di tentukan.

5. Mengembangkan suatu presentasi yang sangat visual untuk area studi yang ditentukan.

Pendidik mengenali bahwa proses pembelajaran secara kritis penting dan pemahaman cara berfikir para siswa adalah kunci peningkatan bidang pendidikan. Perbedaan pemikiran individu dapat diatasi dengan gaya pelajaran sesuai dengan tiga prinsip, yaitu : memperhatikan (vision), mendengarkan (hearing), dan merasakan (feeling). Menurut Cezanne, "Seorang pelukis memerlukan dua hal, mata dan otaknya" [2].

Juga menyimpulkan bahwa menggambar sketsa dengan cara freehand sangatlah diperlukan bagi mahasiswa dan seseorang yang memang bekerja atau dalam beraktifitasnya syarat dengan bahasa visual, terutama bagi mereka yang berprofesi sebagai desainer. Secara tidak disadari bahwa setiap orang dapat menjadi seorang seniman atau artis bahkan des ainer sekalipun tanpa pendidikan formal.

Menggambar tidak dapat di pandang hanya sebagai suatu ketrampilan biasa, di dalamnya terkandung unsur psikologis dan kecerdasan yang mampu memberikan dorongan dan kekuatan dalam menuangkan suatu ide atau persepsi visual. Hal inilah mengapa menggambar menjadi sebuah dasar dalam pembelajaran desain [3]. Sebuah gambar dapat mengekspresikan visi, memberikan solusi yang mungkin, menghasilkan ide, memvisualisasikan proses pemikiran, atau untuk digunakan sebagai 'cara berpikir di atas kertas' [4].

Untuk menjadi seorang desainer produk, gambar harus mewujudkan dan menyampaikan informasi tentang bentuk 
tiga dimensi yang kompleks, memberikan produk baru yang mungkin asing bagi konsumen dengan kepribadian dan kemudahan penggunaan [5].

Pengetahuan yang baik tentang teori ilustrasi dasar seperti perspektif dan bayangan diperlukan untuk membuat sketsa yang kredibel dan menarik [6]. Perspektif adalah gambar objek seperti yang terlihat oleh mata. karena pembuat gambar harus menjaga proporsi bangunan atau arsitek, perspektif selalu dibangun dari rencana dan keting gian [7] dan [8].

\section{METODE}

1. Pengambilan data dan analisis silabus perkuliahan Gambar Bentuk dan Gambar Produk di Departemen Desain Produk dan Departemen Desain Interior untuk mendapatkan referensi mengenai metode menggambar.

2. Membandingkan dan mensintes is hasil analis is tersebut dengan buku yang yang sudah dijadikan sebagai modul ajar sebelumnya sebagai referensi bila ada (studi eksisting).

3. Membuat sketsa contoh rencana materi-materi perkuliahan tersebut sebagai modul ajar.

4. Mengkonsultasikan sketsa rencana materi-materi perkuliahan kepada dosen mata kuliah terkait.

5. Merevisi dan merealisasikan rencana materi-materi menjadi modul ajar (Gambar-gambar 1, 2 dan 3).

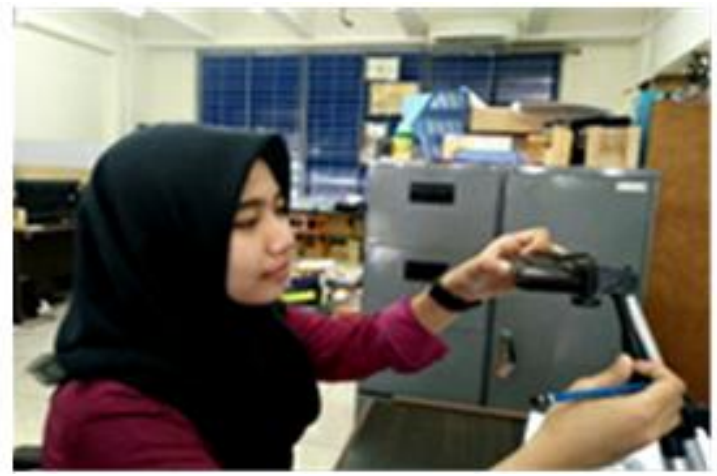

Gambar 1. Mengatur setting kamera

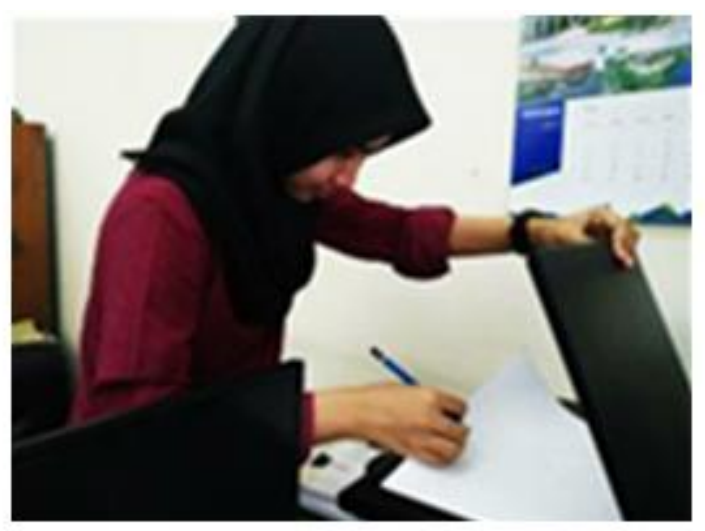

Gambar 2. Sketching bahan ajar.

6. Merancang tata letak (lay out) modul ajar cetak.

7. Mencetak 21 (dua puluh satu) copy purwa rupa modul ajar cetak (dummy) dan mengajukan ISBN.
8. Di waktu yang sama, mendokumentasikan proses pembuatan modul ajar menjadi modul ajar digital yang dapat di unduh.

9. Penyus unan laporan.

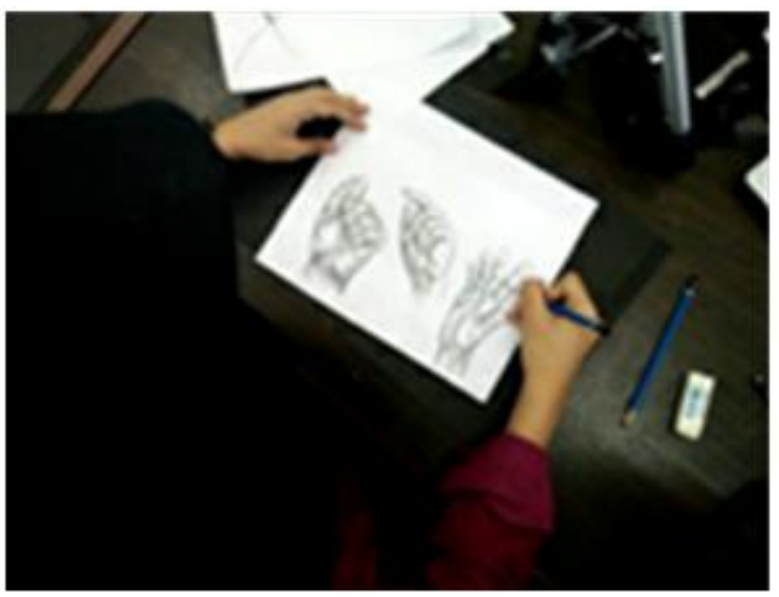

Gambar 3. Scanning modul ajar

\section{HASIL DAN PEMBAHASAN}

Silabus 3 (tiga) departemen Desain di ITS dapat dilihat pada Tabel 1.

Tabel 1. Data Bahan Ajar Berdasarkan Silabus.

\begin{tabular}{|c|c|c|c|}
\hline \multirow{2}{*}{ No. } & \multicolumn{3}{|c|}{ DEPARTEMEN } \\
\hline & DP & DKV & DI \\
\hline 1. & Gambar Anatomi & $\begin{array}{c}\text { Gambar } \\
\text { Anatomi: Kuda }\end{array}$ & Komposisi 2D \\
\hline 2. & $\begin{array}{l}\text { Arsir dan Bangun } \\
\text { Ruang }\end{array}$ & $\begin{array}{c}\text { Komposisi } \\
\text { bangun ruang }\end{array}$ & Komposisi 3D \\
\hline 3. & Still Life & Still Life & $\begin{array}{c}\text { Konst ruksi } \\
\text { Kubus }\end{array}$ \\
\hline 4. & $\begin{array}{l}\text { Konstruksi } \\
\text { Silinder }\end{array}$ & $\begin{array}{c}\text { Texture and } \\
\text { Value: Pohon }\end{array}$ & Texture: Daun \\
\hline 5. & Konstruksi Kubus & $\begin{array}{c}\text { Gambar } \\
\text { Anatomi: Wajah }\end{array}$ & Still Life \\
\hline 6. & Appliance Sketch & $\begin{array}{l}\text { Perspektif } \\
\text { Interior }\end{array}$ & $\begin{array}{l}\text { Perspektif } \\
\text { Interior }\end{array}$ \\
\hline 7. & Gambar Sepatu & Gambar Suasana & \\
\hline 8. & Gambar Furnitur & $\begin{array}{l}\text { Perspektif } \\
\text { Landscape }\end{array}$ & \\
\hline 9. & $\begin{array}{c}\text { Perspektif } \\
\text { Otomotif: Mobil }\end{array}$ & $\begin{array}{c}\text { Perspektif } \\
\text { ot omot if: Mobil }\end{array}$ & \\
\hline 10. & $\begin{array}{c}\text { Perspektif } \\
\text { Otomotif: Motor }\end{array}$ & $\begin{array}{c}\text { Perspektif } \\
\text { Otomotif: Motor }\end{array}$ & $\sim$ \\
\hline 11. & Gambar Sepeda & & \\
\hline 12 . & Perspektif Ruang & & $\sim$ \\
\hline 13. & Gambar Urai & & $\sim$ \\
\hline 14. & $\begin{array}{c}\text { Gambar } \\
\text { Operasional }\end{array}$ & $\sim$ & $\sim$ \\
\hline
\end{tabular}

Berdasarkan data pada Tabel 1 selanjutnya dapat diketahui bahwa ketiga departemen (Desain Produk, Desain Komunikasi Visual, dan Desain Interior) memiliki irisan bahan ajar, yakni gambar anatomi, komposisi bangun 
geometri, still life, konstruksi kubus/ spasial, perspektif otomotif, dan perspektif interior.

Tabel 2.Irisan bahan ajar

\begin{tabular}{|l|l|l|l|l|}
\hline \multirow{2}{*}{ NO. } & \multirow{2}{*}{ BAHAN AJAR } & DP & DKV & DI \\
\hline & & & & \\
\hline 1. & Gambar Anat omi & & & $\sim$ \\
\hline 2. & Komposisi 3D Geometri & & & \\
\hline 3. & Konstruksi Kubus & & & \\
\hline 4. & PerspektifOtomotif: Motor & & & $\sim$ \\
\hline 5. & PerspektifOtomotif: Mobil & & & $\sim$ \\
\hline 6. & Still Life & & & \\
\hline 7. & PerspektifInterior & & & \\
\hline
\end{tabular}

\section{Asis tensi}

Konsultasi contoh sketsa dilakukan pada dosen pengajar mata kuliah terkait.

\section{Sintes is}

Setelah melakukan analisis terhadap hasil konsultasi gambar dengan dosen mata kuliah terkait pada masing- masing departemen, maka diperoleh sintesis mata kuliah Gambar Produk, Gambar Bentuk, dan Gambar Interior (yang dijelaskan pada Tabel 3).

\section{Modul ajar}

Berikut adalah daftar bahan ajar pada seri Modul "Gambar\#1" (dengan salah satu bahan ajar yang beserta langkah-langkahnya):
Bahan ajar 1: Arsir organik kain
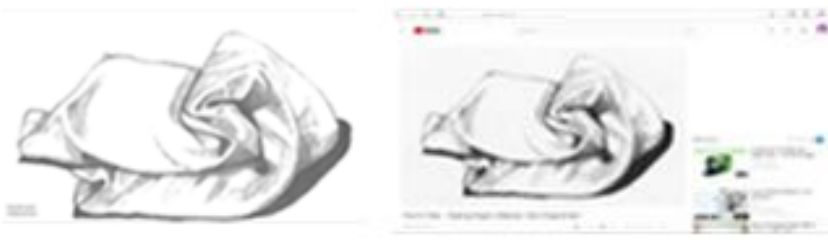

Gambar 4. Modul cetak (kiri) dan digital (kanan) arsir organik kain

Bahan ajar 2: Menguasai garis
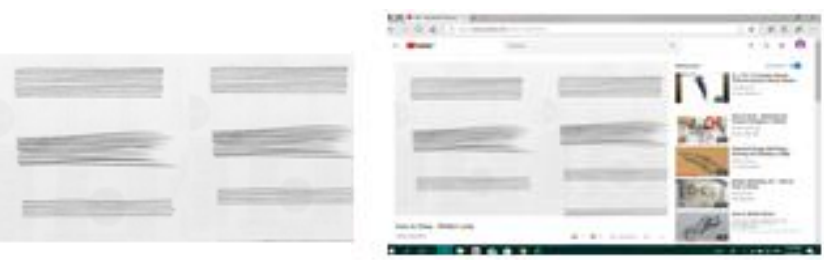

Gambar 5. Modul cetak (kiri) dan digital (kanan) menguasai garis.

Bahan ajar 3: Konstruksi bangun datar (bidang)
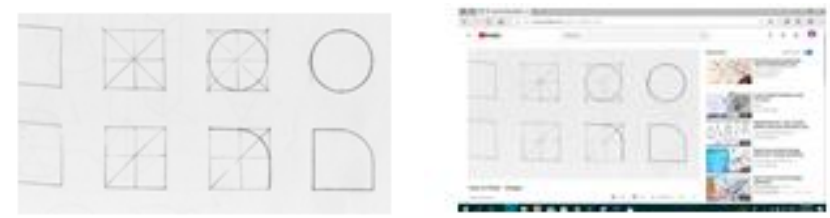

Gambar 6. Modul cetak dan digital konstruksi bangun datar (bidang).

Tabel 3. Sint esis bahan ajar

\begin{tabular}{|c|c|c|c|c|}
\hline \multirow{2}{*}{ No. } & \multirow{2}{*}{$\begin{array}{l}\text { BAHAN } \\
\text { AJAR }\end{array}$} & \multicolumn{3}{|c|}{ MATAKULLAH } \\
\hline & & DP & DKV & DI \\
\hline 1. & $\begin{array}{l}\text { Gambar } \\
\text { Anatomi }\end{array}$ & $\begin{array}{l}\text { Tidak } \\
\text { dipetukan } \\
\text { arsin }\end{array}$ & $\begin{array}{l}\text { Arsir tidak } \\
\text { perhu detal }\end{array}$ & \\
\hline 2. & $\begin{array}{l}\text { Komposist } \\
\text { 3D } \\
\text { Geometri }\end{array}$ & & $\begin{array}{l}\text { Kompostsi } \\
\text { baik, } \\
\text { dinamis } \\
\text { memilliki } \\
\text { irama, serta } \\
\text { perbedamn } \\
\text { jarakyang } \\
\text { vaiatif }\end{array}$ & $\begin{array}{l}\text { Terdin } \\
\text { darin } 5 \\
\text { obyek, } \\
\text { tabung. } \\
\text { kerucut, } \\
\text { kubus, } \\
\text { limas, dan } \\
\text { bola. } \\
\text { Komposia } \\
\text { danteknik } \\
\text { menggam } \\
\text { barbaik }\end{array}$ \\
\hline 3. & $\begin{array}{l}\text { Konstruksi } \\
\text { Kubus }\end{array}$ & & & \\
\hline 4. & $\begin{array}{l}\text { Perspektif } \\
\text { Otomotif: } \\
\text { Motor }\end{array}$ & $\begin{array}{l}\text { Bentuk } \\
\text { terlhat } \\
\text { secara } \\
\text { keselumuhan, } \\
\text { perspektif } \\
\text { dan propersi } \\
\text { benar, } \\
\text { bentuk dan } \\
\text { lineyang } \\
\text { jelas, tidak } \\
\text { perlu } \\
\text { menumjuk- }\end{array}$ & $\begin{array}{l}\text { Angle } \\
\text { menank, } \\
\text { perspektif } \\
\text { tidak terlàs } \\
\text { ditekankan } \\
\text { arsir harus } \\
\text { dapat } \\
\text { mempertha } \\
\text { tkan bentuk } \\
\text { dan } \\
\text { dimensi. }\end{array}$ & \\
\hline 5. & $\begin{array}{l}\text { Perspektif } \\
\text { Otomotif } \\
\text { Mobil }\end{array}$ & $\begin{array}{l}\text { kan detail } \\
\text { mesin. }\end{array}$ & & \\
\hline
\end{tabular}

\begin{tabular}{|c|c|c|c|c|}
\hline \multirow{2}{*}{ No. } & \multirow{2}{*}{$\begin{array}{l}\text { B.AHAN } \\
\text { AJAR }\end{array}$} & \multicolumn{3}{|c|}{ MATAKULLAH } \\
\hline & & DP & DKV & DI \\
\hline 6. & StillLife & $\begin{array}{l}\text { Fokus pada } \\
\text { komposs, } \\
\text { ranah bagus, } \\
\text { terdapat } \\
\text { obyek } \\
\text { berupa } \\
\text { ptoduk, tidak } \\
\text { terlalurealis, } \\
\text { namuntetap } \\
\text { memperthat } \\
\text { kanmaterial. }\end{array}$ & $\begin{array}{l}\text { Variasi } \\
\text { bentuk } \\
\text { dasar culap } \\
\text { banyak, } \\
\text { proporsi } \\
\text { dan strultux } \\
\text { benar, arsir } \\
\text { memperlha } \\
\text { tkan } \\
\text { tekstur. } \\
\text { Dapat } \\
\text { dilakukan } \\
\text { hatehing. }\end{array}$ & $\begin{array}{l}\text { Arsir } \\
\text { dapat } \\
\text { menginfor } \\
\text { masikan } \\
\text { material. } \\
\text { Yang } \\
\text { difokuska } \\
\text { n adalah } \\
\text { ganis } \\
\text { struktur } \\
\text { dan } \\
\text { konstruks } \\
\text { yangbaik }\end{array}$ \\
\hline 7. & $\begin{array}{l}\text { Perspektif } \\
\text { Intenior }\end{array}$ & $\begin{array}{l}\text { Perspektif } \\
\text { benar, ranah } \\
\text { yangbaik, } \\
\text { dan fokus } \\
\text { padakusen } \\
\text { kusendan } \\
\text { produk } \\
\text { interior, } \\
\text { namuntidak } \\
\text { terlalu } \\
\text { kompleks }\end{array}$ & $\begin{array}{l}\text { Finishing } \\
\text { cukup } \\
\text { dilakukan } \\
\text { dengan } \\
\text { arsir pensil }\end{array}$ & $\begin{array}{l}\text { Tidak } \\
\text { terfokus } \\
\text { padastill } \\
\text { life, flora, } \\
\text { dan faura } \\
\text { Menekark } \\
\text { anpada } \\
\text { kontruksi } \\
\text { elemen } \\
\text { interior } \\
\text { dan } \\
\text { komposisi } \\
\text { fumiture } \\
\text { yangbaik. }\end{array}$ \\
\hline
\end{tabular}


Bahan ajar 4: Menggambar perspektif sederhana (dengan karet)
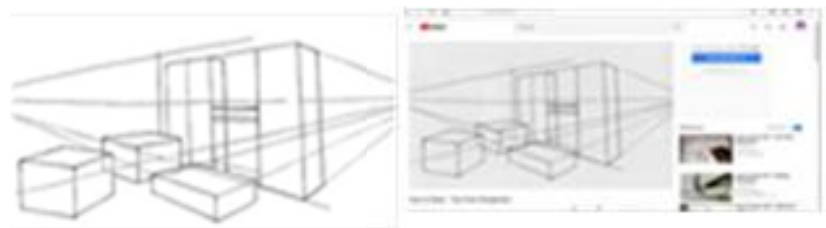

Gambar 7. Modul cetak dan digital menggambar perspektif sederhana (dengan karet).

Bahan ajar 5: Menggambar bayangan
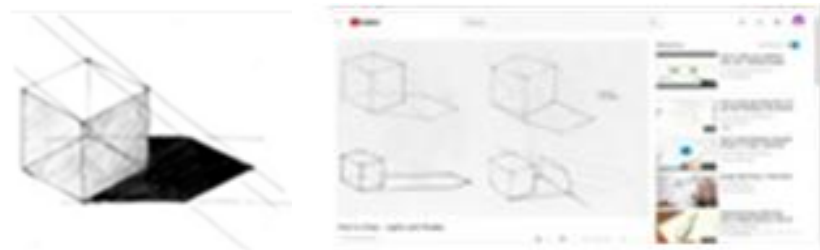

Gambar 8. Modul cetak dan digital menggambar bayangan.

Bahan ajar 6: Komposisi bangun ruang
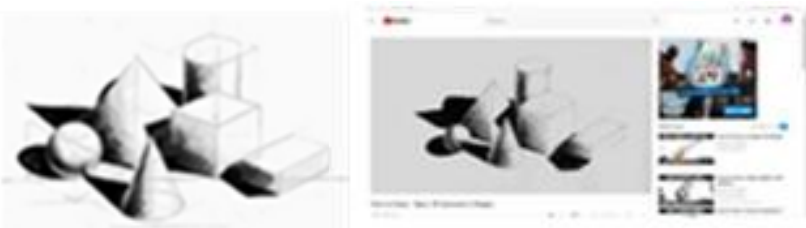

Gambar 9. Modul cetak dan digital komposisi bangun ruang.

Bahan Ajar 7: Menggambar balok 1
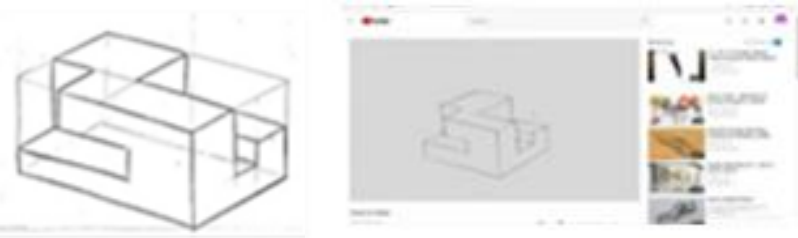

Gambar 10. Modul cetak dan digital menggambar aalok 1 .

Bahan ajar 8: Menggambar balok 2
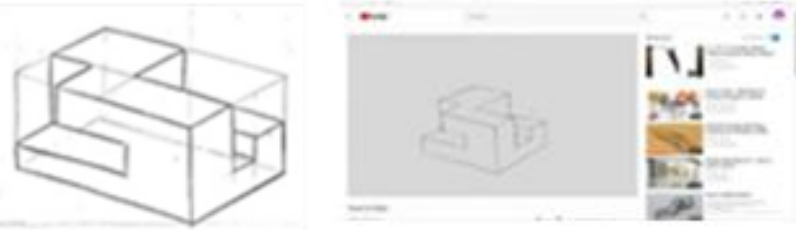

Gambar 10. Modul cetak dan digital menggambar aalok 1.

Bahan ajar 9 : Menggambar paralon
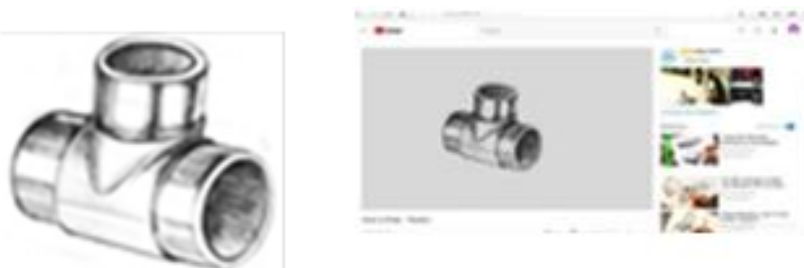

Gambar 12. Modul cetak dan digital menggambar paralon.
Bahan ajar 10 : Furnitur sederhana
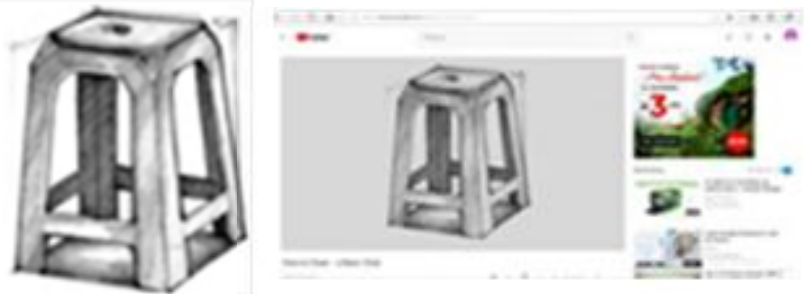

Gambar 13. Modul cetak dan digital furnitur sederhana

Bahan ajar 11: Obyek kompleks
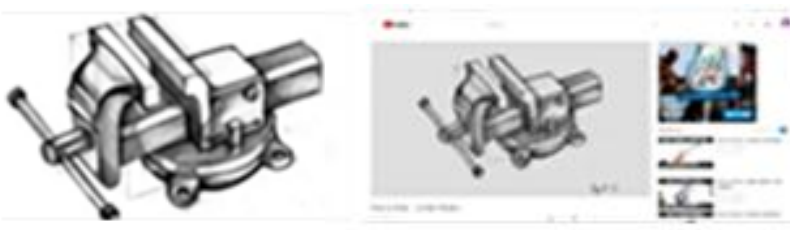

Gambar 14. Modul cetak dan digital obyek kompleks.

Bahan ajar 12: Still life
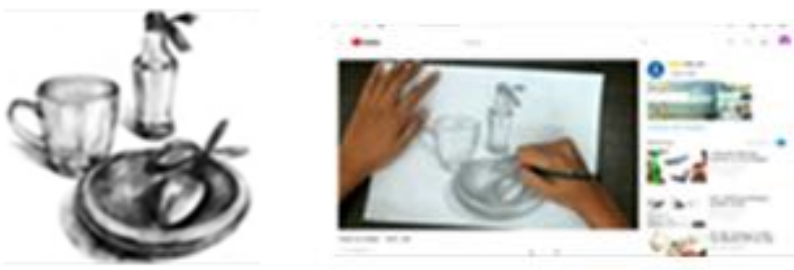

Gambar 15. Modul cetak dan digital life style

Bahan ajar 13 : Menggambar figur
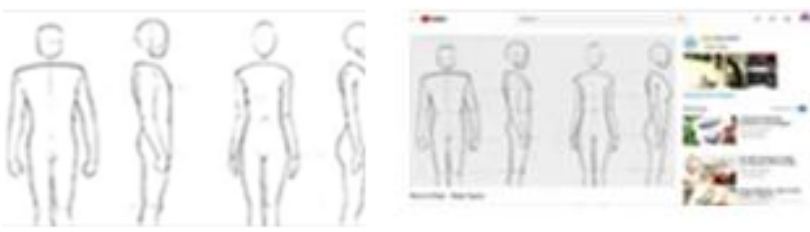

Gambar 16. Modul cetak dan digital menggambar figur.

Bahan ajar 14: Figur Organ
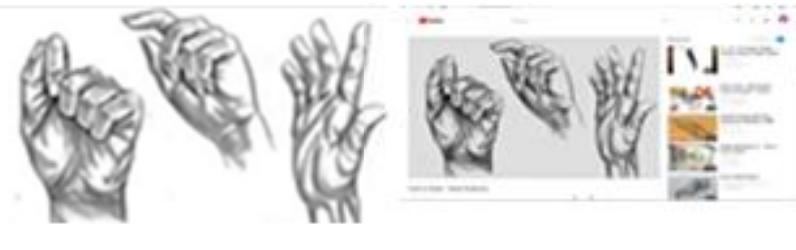

Gambar 17. Modul cetak dan digital figur organ

Bahan ajar 15: Gambar gestur manus ia
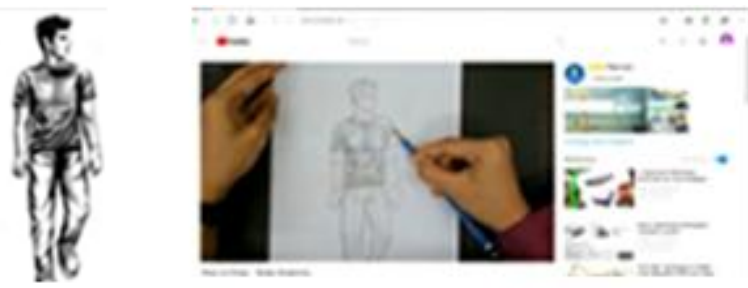

Gambar 18. Modul cetak dan digital gambar gestur manusia. 
Bahan ajar 16: Gambar interaksi tangan

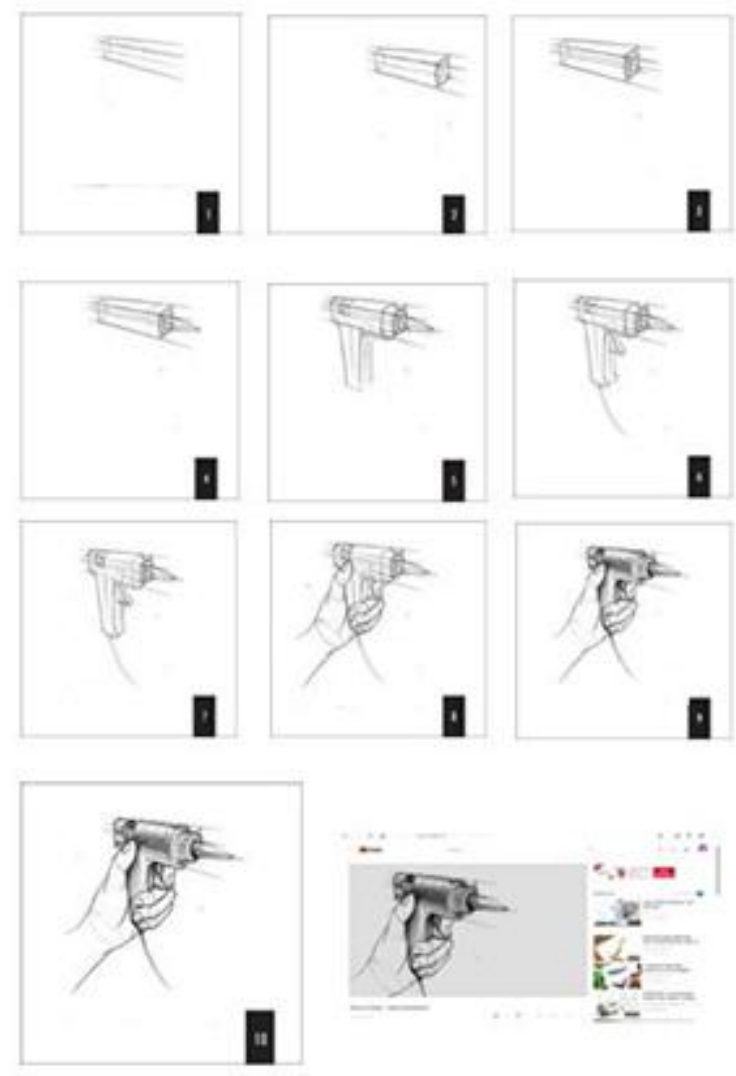

Gambar 19. Modul cetak dan digital gambar int eraksi tangan

\section{KESIMPULAN \& SARAN}

\section{Cetak}

Dengan penelitian ini, maka dapat disimpulkan bahwa bahan ajar untuk mata kuliah Gambar Produk, Gambar Bentuk, dan Gambar Interior antara lain: Gambar Anatomi, Komposisi 2D, Komposisi Bangun Ruang, Still Life, Konstruksi Kubus, Texture and Value (Pohon, dan Daun),
Gambar Suasana, Appliance Sketch, Gambar Sepatu, Gambar Furnitur, Gambar Sepeda, Gambar Urai, Gambar Operasional, Perspektif Interior, Perspektif Lansekap, dan Perspektif Otomotif.

Materi- materi ajar di atas akan dijadikan menjadi sebuah modul ajar yang disesuaikan dengan kebutuhan mahas iswa masing- masing departemen melalui proses sintesis yang akan diterbitkan dalam 3 serial modul ajar, yaitu "Gambar\#1", "Gambar\#2", dan "Gambar\#3"

\section{Digital}

Modul ajar secara digital dibuat dalam bentuk video tutorial yang diunggah melalui akun "Dosen Sketsa Pens il" pada media sosial YouTube.

Link:

https://www.youtube.com/channel/UCQmPzoA0s YMxGx9 R8d13Pzw

\section{DAFTAR PUSTAKA}

[1] Nefo, Amirul, "Analisa Peran Sketsa dalam Pendidikan Desain Produk dengan Pendekatan Multiple Intelligence", Thes is, ITB (2004)

[2] Gollwitzer, Gerhard, "Menggambar bagi Pengembangan Bakat", Penerbit ITB (1986)

[3] Sachari, Agus, "Seni Rupa dan Desain kelas X,-XII", Jakarta : Erlangga (2006)

[4] Eissen, Koos, \& Steur, Ros elien, "Sketching : Drawing Technique for Product Designer", Bis Publisher (2009)

[5] Pipes, Alan, "Drawing for Designer", Laurence King Publishers (2007)

[6] Erik Olofss on \& Klara Sjölén, "Design Sketching", KEEOS Design Books, Sweden (2005)

[7] Waluyohadi, "Gambar Bentuk dan Suasana", Butawarna Publishing (2015)

[8] Atkin, William W., Raniero Corbelletti, dan Vincent R.Fiore, "Pencil Techniques in Modern Design", Reinhold Publishing Corporation (1962) 